\title{
CEMENTED DUAL MOBILITY CUPS IN PRIMARY TOTAL HIP ARTHROPLASTY IN PATIENTS AT HIGH RISK OF DISLOCATION
}

\author{
Amr Khairy Mahmoud, Osama Mohamed Farag, Magdy Saad Mahmoud, \\ Mostafa Mamdouh Ashoub, Ahmed Mohamed Sallam, \\ and Mohamed Ibrahim Mohamed Mohamed
}

\begin{tabular}{l}
\hline \\
Department Orthopaedic \\
Surgery, Faculty of Medicine - \\
Ain Shams University \\
, Cairo, Egypt \\
Corresponding Author: \\
Mohamed Ibrahim Mohamed \\
Mobile: (+2) 01007016177 \\
E-mail: \\
mohamedelghazalawy@gmail. \\
com \\
Received: 30/8/7/2020 \\
Accepted: 20/8/2020
\end{tabular}

Online ISSN: 2735-3540

\begin{abstract}
:
Background: Although total hip replacement (THR) remains one of the most successful procedures in modern orthopedic surgery, complications may occur. Dislocation is one of the major complications that may increase the hospital length of stay and even lead to a revision arthroplasty. Instability after total hip replacement can occur in $2 \%$ to $7 \%$ in primary cases and can reach up to $25 \%$ to $30 \%$ in revision cases and the majority of the dislocating events occur during the first three months after surgery.
\end{abstract}

Aim of the Work: To evaluate DM cups as a treatment option in selected group of patients at an elevated risk for instability after primary THA and will focus on dislocation and early implant survival following surgery.

Patients and Methods: In the period between September 2017 to March 2020 a prospective study was conducted involving 20 patients with high risk of dislocation underwent total hip replacement using dual mobility cup either as primary hip arthroplasty or after failed fixation of proximal femoral fractures. The last case was operated at February 2018. All cases were operated upon in Ain Shams University Hospitals and the follow up of the cases was 2 years.

Results: There were no case showed dislocation or intraprosthetic dislocation till the last follow up.

Conclusion: In this study 1 case had complication. The complication was peri-prosthetic fracture after a fall while the prosthesis remain stable and was managed with reduction and fixation and the fracture healed with good final results and no intraoperative complication occurred with total complications rate 5\%. This study showed that Dual mobility cups are efficient technique in preventing hip arthroplasty instability with good clinical results.

Keywords: Dual mobility cups, intraprosthetic dislocation, range of motion

\section{INTRODUCTION:}

Hip arthroplasty is associated with improved function and quality of life $\mathrm{e}^{(1)}$. Dislocation after total hip arthroplasty (THA) remains a troublesome complication and a source of frustration for the patient and the surgeon ${ }^{(2)}$. Early recurrent dislocation may lead to revision surgery and is associated with high risk of complications ${ }^{(1)}$. The prevalence of reoperation for instability is highly variable and is reported approximately as $1 / 3$ of the dislocating THAs $^{(3,4)}$. 


\section{Amr Khairy Mahmoud, et al.,}

Patients with neuromuscular and cognitive disorders consistently demonstrated a higher risk for postoperative dislocation $^{(5,6,7)}$. Muscle weakness, general imbalance and inability to comply with activity restrictions are all considered to be the likely causative factors ${ }^{(8)}$.

The use of constrained components is one option for treating and preventing recurrent dislocation of THRs. The mean rate of dislocations following revision surgery with a constrained component has been reported to be $10 \%$. Furthermore, constrained components are associated with high rates of aseptic loosening in the long term. Another treatment option for recurrent dislocations is the use of a dual-mobility cup. $^{(9)}$

The concept of dual mobility articulation was developed in 1970 by Bousquet to increase the range of motion and to decrease dislocation risk. It combined a small head to decrease wear (low friction arthroplasty principles stated by Charnley ${ }^{(10)}$ and a large head to increase stability (MacKee and Farrar ${ }^{(11)}$. Several studies have looked at the outcome of dual mobility articulation in primary THR and in revision $\mathrm{THR}^{(12)}$.

The use of a cemented dual mobility hip prosthesis to manage unstable THAs is an attractive option. Encouraging results have been reported with the use of such implants in primary THAs to prevent instability (13). Some authors use the dual mobility (DM) cups as the first choice for patients at risk for dislocation ${ }^{(1)}$.

Dual mobility cups have been reported to have a low rate of postoperative dislocation in elective surgery, not only in primary total hip arthroplasties, but also in revision procedures and most particularly as a treatment for recurrently dislocating hip replacements. Do these implants also perform well in the setting of femoral neck fractures in the elderly patients and patients with expected higher rate of postoperative instability and is there an advantage to using such implants to prevent postoperative dislocation? This study will be conducted to get an answer.

\section{AIM OF THE WORK}

The aim of this work is to evaluate DM cups as a treatment option in selected group of patients at an elevated risk for instability after primary THA and will focus on dislocation and early implant survival following surgery.

\section{PATIENTS AND METHODS}

Number of cases: In the period between September 2017 to March 2020 a prospective study was conducted involving 20 patients with high risk of dislocation underwent total hip replacement using dual mobility cup either as primary hip arthroplasty or after failed fixation of proximal femoral fractures. The last case was operated at February 2018. All cases were operated upon in Ain Shams University Hospitals and the follow up of the cases was 2 years.

\section{Methodology:}

Preoperative, intraoperative and postoperative components.

\section{Preoperative Component:}

It included: Patient selection. Patient counseling. Patient evaluation: Clinical evaluation (history, general examination and local examination). Harris Hip Score. ${ }^{(14)}$ Radiological evaluation. Preoperative preparation of the patient.

\section{Patient Selection:}

Inclusion Criteria: The indications of inclusion in the study are all cases with indication of hip arthroplasty that have increased risk of post-operative instability: Femoral neck or proximal femoral fracture 
with stroke with documented neurological deficit with muscle weakness (grade four, three or two) on the operated side. Failed proximal femoral fracture fixation with stroke with documented neurological deficit with muscle weakness (grade four, three or two) on the operated side. Patients aged 70 or older with a diagnosis of a displaced intracapsular femoral neck fracture. Femoral neck fracture with cognitive dysfunction. Primary THA after tumor resection. Hip arthroplasty in patients with American Society of Anesthesiologists score (ASA) of 3 or 4 . Poor soft tissue envelope around the hip eg. rheumatoid or due to repeated hip surgery.

Exclusion Criteria: Patients with no muscle weakness or with severe weakness (grade one or zero). Active infection. Bad general condition in which the patient is not fit for surgery (ASA V). Non-ambulant patients.

Patient Counseling: Is a crucial part of the procedure. The proposed plan including the investigations necessary for the surgery, the operative details, the postoperative rehabilitation program, the average time of rehabilitation and possible complications were discussed with the patients in full details. This Counselling was essential to have the maximum cooperation of the patient.

Patient evaluation: Each patient in this study was carefully assessed clinically in the form of detailed clinical history and thorough examination.

\section{Clinical history:}

We were aiming in this part to: Carefully identify the detailed history that led to affection and current condition of the hip. Identify any patient factor claimed with higher incidence of infection in the proposed surgery e.g. any potential source of infection in the patient body, medications affecting immunity and diabetes mellitus. Identify patient medical co-morbidities and past surgical history Preassess the patient by anaesthesiologist to identify fitness and prerequisites of surgery.

\section{Patient examination:}

General assessment: This was done to assess the patient general fitness for such a major surgery, to identify potential sources of infection and may help to reach the etiology of the hip condition, high risk for dislocation, associated medical condition and evaluate ASA score.

Local examination: Complete local examination of the involved hip joint was routine with particular emphasis on the following issues: Limb length discrepancy, abductor strength, scars of operations, neurovascular status and harris hip score ${ }^{(14)}$

\section{Radiological Evaluation:}

Anteroposterior projection ${ }^{(15)}$. To perform proper templating, it is important to be minded by the anatomical landmarks: teardrop, ischial tuberosities, top of the lesser trochanter, top of the greater trochanter, lateral superior edge of the acetabulum and normal centre of rotation of the normal hip.

After anatomical landmarks were recognised, radiographs should be examined for: Limb length inequality and the medial femoral offset: The medial femoral offset was estimated on the contralateral normal hip, as restoring the normal degree of offset is a primary goal of hip replacement.

\section{Templating:}

The general goals were mainly to restore as nearly as possible the anatomic hip centre of rotation and femoral offset and equalizing limb length discrepancy if present. 
A) Acetabular side templating:

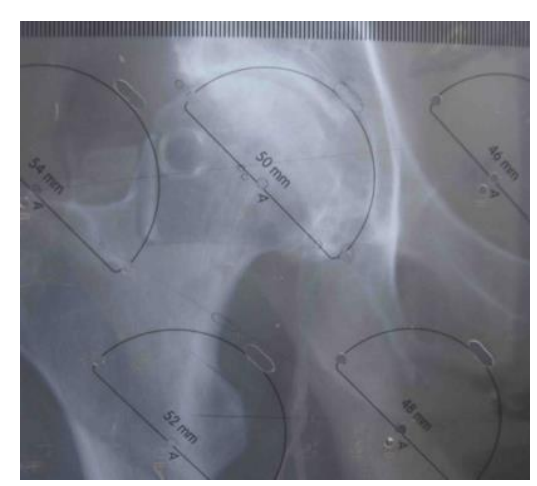

Fig. (1): Acetabular templating.

Femoral side templating: We placed the femoral overlay templates on the film and selected the size that most precisely matched the contour of the proximal canal and fills it most completely. Next, we selected the appropriate neck length to restore limb length and femoral offset.(fig1)

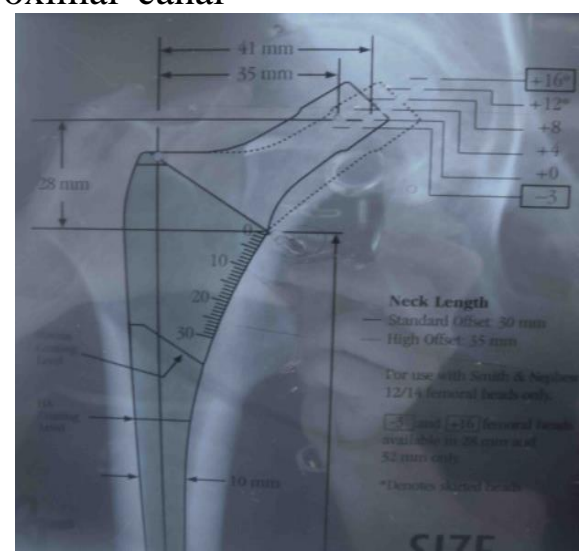

Fig. (2): Femoral templating.

Preoperative preparation of the patient: Beside the routine preoperative investigations that were carried out for all patients, further special investigations were requested by anaesthesiologist according to each case to complete anaesthetic judgment. Preoperative haemoglobin was at least 10 $\mathrm{g} / \mathrm{dl}$ in all patients. Two units of blood were prepared for each patient, but their use was according to the individual situation. Preoperative hydration: one liter of Ringer's solution at the operation morning. All the patients received a single dose of prophylactic antibiotic third generation cephalosporin $1000 \mathrm{mg}$ before induction of anesthesia preoperative and continued for 5 days postoperatively.

Operative Procedure: Anaesthetic technique, asepsis and Antibiotics.

\section{Operative Technique:}

Exposure:

Rady's approach ${ }^{(16)}$ (a modified lateral approach) was used in all cases. 


\section{Acetabular preparation:}

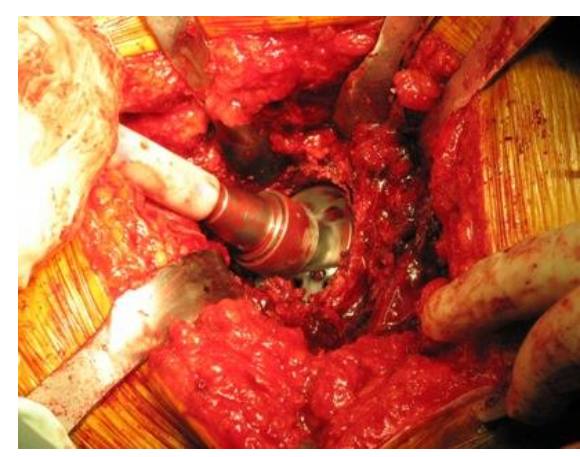

Fig. (3): Reaming of the acetabulm.

When reaming reached this concentric socket and bleeding subchondral bone and adequate reamer size, a trial cup was inserted to check the size and fitting, then the original cup was inserted. (fig. 4,5,6)

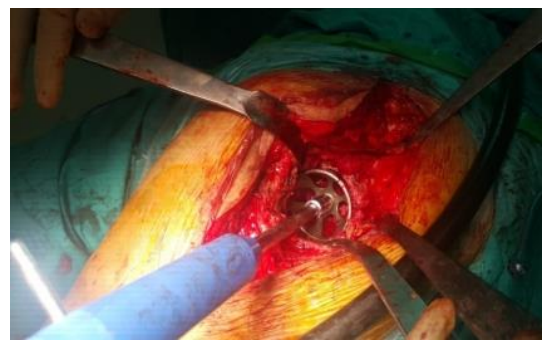

Fig. (4): Trial acetabular cup.

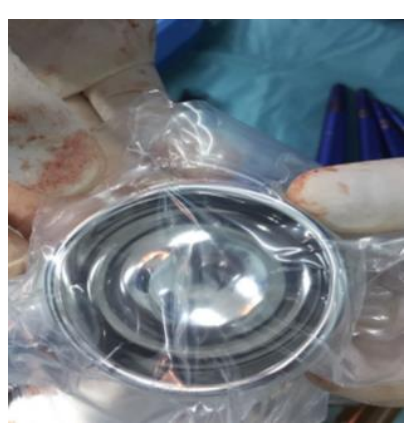

Fig. (5): Cemented acetabular metal shell.

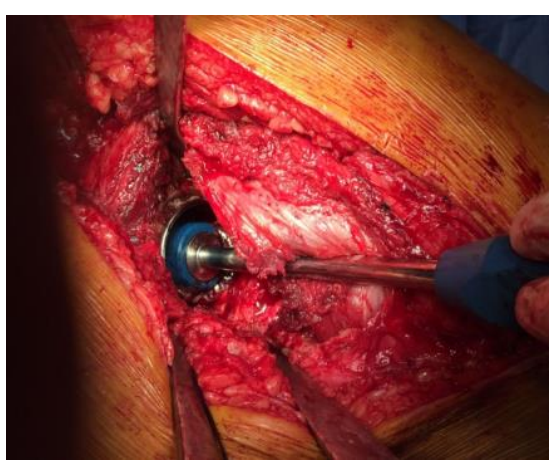

Fig. (6): Acetabular shell impacted into acetabulm.

\section{Femoral preparation:}

was increased gradually until reaching a broach size that was rotationally stable and

Femoral side preparation was then started with a cancellous bone impactor does not subside with hammering. (fig. 7) followed by a small broach. The broach size

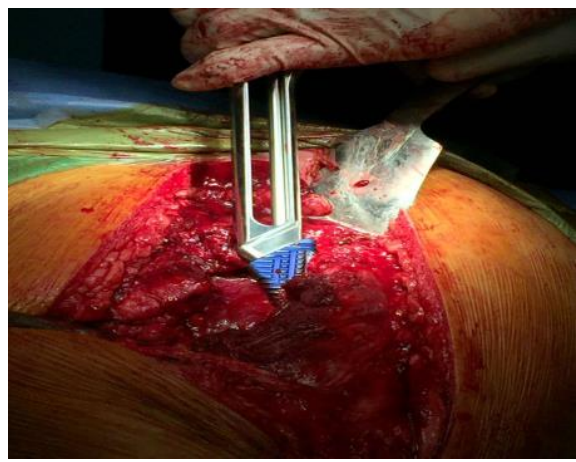

Fig. (7): Femoral broaching.

Trial of reduction was done with the chosen femoral broach using a trial head with the proper length.
After ensuring good orientation, the femoral broach was removed and the actual stem was inserted.

Trial of reduction was repeated with the actual stem. After ensuring proper 
orientation and determining the length of the head needed, assembly of the metal head with mobile polyethylene liner with compression device is done. (fig. 8,9)

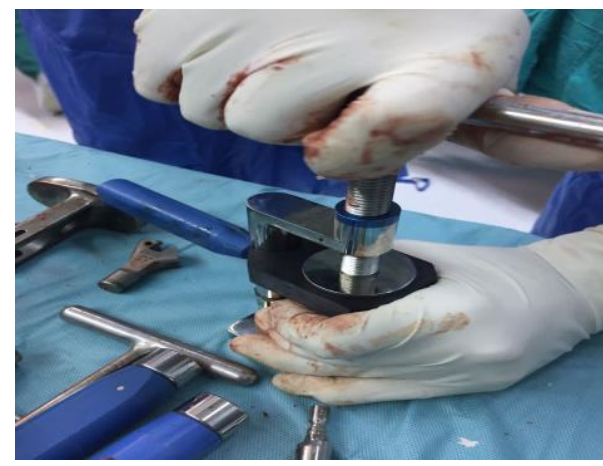

Fig. (8): Compression device.

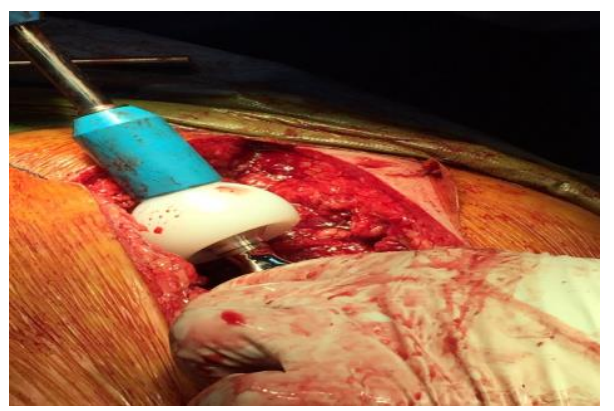

Fig. (10): Head-polyethylene unit introduced over the stem.

\section{Wound closure:}

The gluteus minimums was sutured with the hip in abduction and internal rotation, followed by the gluteus medius in the same position, then, the iliotibial band was sutured after application of a suction drain.

After subcutaneous and skin closure, the patient was brought back to the supine position while holding the limb in abduction and internal rotation.

\section{Postoperative Component:}

\section{Patient transfer procedure:}

The transfer procedure was supervised by the surgeon or at least his assistant. The patient was directly transferred from the operating room to his/her bed, the surgeon held the legs with the operated hip abducted
The assembled head-polyethylene liner is impacted over the actual stem then introduced into the acetabular shell. (fig. 10,11).

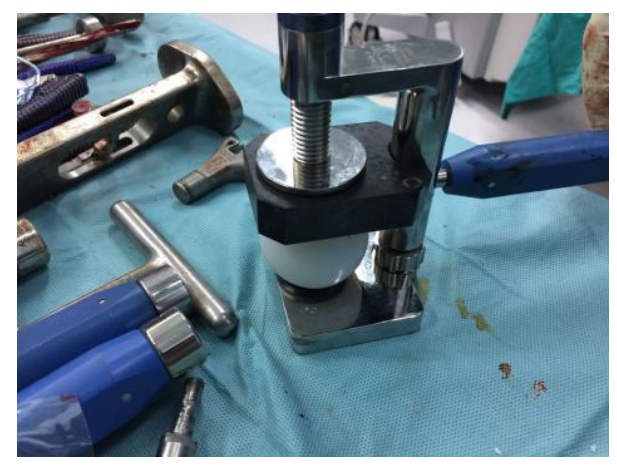

Fig. (9): Assembly of metal head into mobile polyethylene liner.

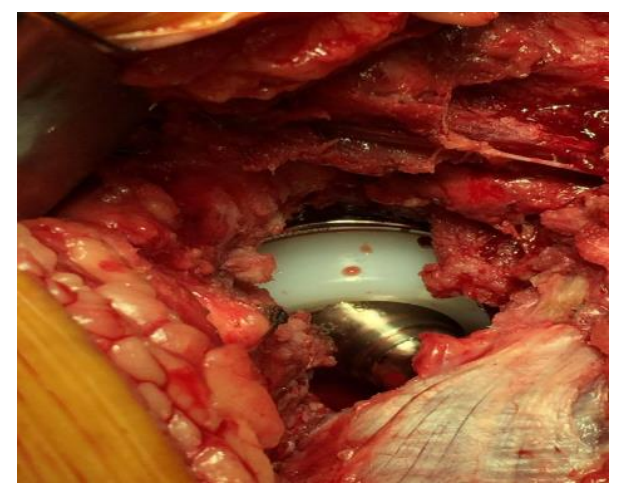

Fig. (11): Prosthesis reduced into acetabular metal shell.

and internally rotated. The anesthetist looked after the head and neck.

\section{Recovery room:}

In the recovery room, the patient was observed by a nurse and pulse oximeter was used to record the pulse and the oxygen saturation. The blood pressure was also checked and analgesia was started.

\section{In the Ward:}

\section{Antibiotics:}

All patients received intravenous third generation cephalosporin for 5 days postoperatively, then patient was discharged from the hospital on oral broad spectrum antibiotics, and continued till stitches removed (15days from the surgery). 


\section{Anticoagulants:}

All patients received low molecular weight heparin during hospitalization, followed by oral anticoagulants after discharge and for 6 weeks.

\section{Hemoglobin level:}

Hemoglobin level was checked in the first postoperative day and blood transfusion was given if necessary.

\section{Wound condition:}

Wound condition was followed during the first 2 weeks, which is the time by the end of which the wound is supposed to be healed and the stitches are removed.

\section{Ambulation protocol:}

Immediate hip and knee flexion, rapid foot pumps, and deep breathing exercises were emphasized to minimize thromboembolic and pulmonary complications.

Walking was started on the first postoperative day. Weight bearing as tolerated is allowed, and all cases were instructed to be full weight bearing immediately after the operation, and the supporting method was used for balance only in the form of a walker or 2 crutches.

In Patients with transfemoral osteotomy and patients with graft reconstruction of acetabular defects weight bearing was delayed for 6 weeks, then started after that gradually with walking aids as described above.

\section{Radiological Evaluation:}

Anteroposterior radiograph of the pelvis was taken to assess: The femoral offset. Acetabular inclination was determined in relation to the inter teardrop line (ideally $45^{\circ}$ ). Femoral stem orientation was assessed (ideally neutral or slight valgus $\left.5^{\circ}\right)$.

After discharge: All patients had clinical and radiological evaluation at regular periods during their follow up.

Clinical evaluation: Harris hip score was used for clinical evaluation of patients at 6 weeks, 6 months, and last follow up.

Radiographic evaluation: Standard radiographs were made for all patients at subsequent follow up examinations. The radiographs were examined for: Component position or migration. Osteolysis and loosening. Union of transfemoral osteotomy if used.

\section{Statistical analysis:}

Recorded data were analyzed using the statistical package for social sciences, version 20.0 (SPSS Inc., Chicago, Illinois, USA). Quantitative data were expressed as mean \pm standard deviation (SD). Qualitative data were expressed as frequency and percentage.

The following tests were done: Paired sample t-test of significance was used when comparing between related sample. The confidence interval was set to $95 \%$ and the margin of error accepted was set to $5 \%$. So, the $\mathrm{p}$-value was considered significant as the following: Probability (P-value): P-value $\leq 0.05$ was considered significant. P-value $\leq 0.001$ was considered as highly significant. $\overline{\mathrm{P}}$-value $>0.05$ was considered insignificant. 


\section{RESULTS}

Table (1): Distribution of patients at high risk of dislocation according to their demographic data regarding sex and age $(n=20)$.

\begin{tabular}{|c|c|}
\hline \multicolumn{1}{|c|}{ Demographic data } & Total $(\mathrm{n}=20)$ \\
\hline Sex & \\
\hline Female & $9(45 \%)$ \\
\hline Male & $11(55 \%)$ \\
\hline Age (years) & \\
\hline Range & $58-78$ \\
\hline Mean \pm SD & $65.85 \pm 5.58$ \\
\hline Median (IQR) & $65(7)$ \\
\hline
\end{tabular}

* Median and Interquartile range (IQR)

There were different indications of Dual mobility cup in the study group with failed fixation of hip fracture representing ( 3 cases) $15 \%$.

Fracture neck of femur comprise 6 cases $(30 \%)$ of the study group while intertrochantric fracture femur comprises 4 cases $(20 \%)$ while pathological fracture of proximal femur represents 1 cases $(5 \%)$ of the study group while osteoarthritis comprises 4 cases $(20 \%)$ and failed proximal femoral fixation 5 cases $(25 \%)$.

Table (2): Distribution of patients according to their diagnosis $(n=20)$.

\begin{tabular}{|l|c|c|}
\hline \multicolumn{1}{|c|}{ Diagnosis } & No. & $\%$ \\
\hline Fracture neck femur & 6 & 30 \\
\hline Intertrochantric fracture & 4 & 20 \\
\hline Osteoarthritis & 4 & 20 \\
\hline Failed proximal femur fixation & 5 & 25 \\
\hline Pathological fracture of proximal femur & 1 & 5 \\
\hline Total & 20 & 100 \\
\hline
\end{tabular}

Patient related risk factor of dislocation were variable for each patient. 55\% of patients (11 cases) had 1 risk factors of dislocation, 35\% (7 cases) had 2 risk factors while 10\% of patients ( 2 cases) had 3 risk factor of dislocation.

Table (3): Distribution of patients at high risk of dislocation according to their risk factor of dislocation $(n=20)$.

\begin{tabular}{|l|c|c|}
\hline \multicolumn{1}{|c|}{ Risk Factor of dislocation } & No. & $\%$ \\
\hline 1 Factor & 11 & 55 \\
\hline 2 Factors & 7 & 35 \\
\hline 3 Factors & 2 & 10 \\
\hline Total & 20 & 100 \\
\hline
\end{tabular}

\section{Harris hip score:}

Harris hip score was used for clinical evaluation of patients, pre and postoperatively at 6 weeks, 6 months, and last follow up for twenty five hips. 
Table (4): The extent of the difference over the periods through HHS in the study group.

\begin{tabular}{|l|c|c|c|c|c|}
\hline \multicolumn{1}{|c|}{ HHS } & Range & Mean \pm SD & Mean Diff. & $\begin{array}{c}\text { Paired Sample t- } \\
\text { test }\end{array}$ & p-value \\
\hline Pre & $14-44$ & $25.95 \pm 9.91$ & & & \\
\hline After 6 weeks & $55-68$ & $62.05 \pm 3.93$ & 36.1 & -15.038 & $<0.001^{* *}$ \\
\hline After 6 months & $85-98$ & $91.35 \pm 3.30$ & 65.4 & -31.473 & $<0.001^{* *}$ \\
\hline After 2 years & $88-98$ & $92.45 \pm 2.74$ & 66.5 & -32.459 & $<0.001^{* *}$ \\
\hline
\end{tabular}

Using: Paired Sample t-test; **p-value <0.001 HS

This table shows highly statistically significant difference between pre and other measurements according to HHS.

Dislocation and Intraprosthetic dislocation:

Table (5): Distribution of patients at high risk of dislocation according to their dislocation $(n=20)$.
Among the twenty patients of the study group with high risk of dislocation no large articulation dislocation or intraprosthetic dislocation were encountered till the last follow up.

\begin{tabular}{|l|c|c|}
\hline \multicolumn{1}{|c|}{ Dislocation } & No. & \% \\
\hline No & 20 & 100 \\
\hline Yes & 0 & 0 \\
\hline Total & 20 & 100 \\
\hline
\end{tabular}

\section{Complications:}

In this study 1 case had complication. The complication was peri-prosthetic fracture after a fall while the prosthesis remain stable and was managed with reduction and fixation and the fracture healed with good final results and no intraoperative complication occurred with total complications rate $5 \%$.

Table (6): Distribution of patients at high risk of dislocation according to their complications $(n=20)$.

\begin{tabular}{|l|c|c|}
\hline \multicolumn{1}{|c|}{ Complications } & No. & $\%$ \\
\hline No & 19 & 95 \\
\hline peri-prosthetic fracture & 1 & 5 \\
\hline Total & 20 & 100 \\
\hline
\end{tabular}

\section{DISCUSSION}

Hip arthroplasty is associated with improved function and quality of life ${ }^{(1)}$. Dislocation after total hip arthroplasty (THA) remains a troublesome complication and a source of frustration for the patient and the surgeon ${ }^{(2)}$. Early recurrent dislocation may lead to revision surgery and is associated with high risk of complications ${ }^{(1)}$. The prevalence of reoperation for instability is highly variable and is reported approximately as $1 / 3$ of the dislocating THAs. ${ }^{(3,4)}$.

Instability after a total hip arthroplasty remains a troublesome complication. Identification of patients at risk for dislocation is a crucial preoperative measure to prevent the occurrence of hip instability specially in critically ill patient who cannot tolerate repeated surgeries.

The dual mobility cups (DMC) designed by Gilles Bousquet are used in an expanding range of indications. This implant has been demonstrated to improve hip stability in primary total hip arthro-plasty (THA) and recurrent hip dislocation after THA. Theoretically, the design should reduce the risk of dislocation according to two principles: the mobile insert should minimize prosthetic neck impingement over the polyethylene component and the large articulation between the insert and the 
metallic shell should increase ROM before dislocation with increase of jumping distance. ${ }^{(17)}$

This study is a prospective one that questions the effectiveness of the use of cemented dual mobility cup in THA in a selected group of patients with anticipated increased risk of dislocation after hip replacement for different indications. It was conducted in the period between September 2017 to March 2020, involving 20 patients with high risk of dislocation. The last case was operated at February 2018, 9 cases were females and 11 cases were males. The mean age of the study group is 65.8 years. All cases were operated upon in Ain Shams University Hospitals with follow up of 2 years at least.

The indications for cemented dual mobility cup were variable and included: Fracture neck of femur comprise 6 cases $(30 \%)$ of the study group while intertrochantric fracture femur comprises 4 cases $(20 \%)$ while pathological fracture of proximal femur represents 1 cases $(5 \%)$ of the study group while osteoarthritis comprises 4 cases $(20 \%)$ and failed proximal femoral fixation 5 cases $(25 \%)$.

In this study, the following were considered as risk factors of dislocations rendering the patients at high risk of dislocation are: Old age (more than 60 years), previous hip surgery (e.g., failed proximal femoral fracture fixation), post traumatic eg, femoral neck fracture with neuromuscular disease (e.g., epilepsy, Parkinson's disease, and myopathy, cerebrovascular stroke), cognitive dysfunction (e.g., dementia and Alzheimer's disease), American society of anesthesia score more than 3 and pathological fracture of proximal femur.

Benjamin A. McArthur et al. ${ }^{(18)}$ in their review paper of dual mobility acetabular cup advocated its use in patients with increased dislocation risk, including those undergoing revision THA for recurrent instability, revision THA for all other causes, THA after femoral neck fracture, and THA after tumor resection. Initial indications for DM components at their institution were for primary THA in elderly women with ligamentous laxity and revision THA in the setting of recurrent dislocations despite appropriate component position.

Olivier Guyen et al. ${ }^{(2)}$ advocates the use of DM cups to treat instability in three situations: patients in whom no identifiable cause for instability could be identified or corrected, patients in whom prior surgical attempts at stabilization failed, and patients with a marked deficiency of the hip abductors; instead of a constraining device given the previously raised concerns regarding the potential for loosening and failure with constrained implants.

There are few studies in the literature regarding DM THA for fracture neck of femur treatment. However, some recent reports demonstrate a growing interest on this topic. In particular, the theoretical advantage of a very low dislocation rate together with good clinical results reported in the literature about OA might have lead to the growing indication for DM THA in fracture neck of femur treatment.

In a recent review ${ }^{(19)}$ these studies were analyzed and compared with the literature about fracture neck of femur treatment with other implants. The results in terms of patients demographic characteristics and mortality were in line with the literature ${ }^{(20)}$. Conversely, a relevant amount of neuromuscular diseases and cognitive impairment incidence (up to $42 \%$ of cases) was recorded ${ }^{(21)}$. Nonetheless, Graversen et al. (22) conducted a study on 20 patients affected by dementia which the authors considered an ideal indication for DM THA. These data reflect the clinicians' choice to implant DM THA in patients at maximal risk of prosthetic dislocation. In our study we had operated 5 cases of fracture neck 
femur with neurological disease 3 of them had previous history of stroke, 1 case on anti-epileptic medication and 1 case had Alzheimer disease and no one had dislocated during our follow up.

The systematic use of total hip arthroplasties to treat displaced intracapsular fractures of the proximal femur in elderly patients is not common practice. Postoperative dislocation is a key issue when treating displaced fractures of the femoral neck. One of the potential drawbacks of performing a total hip arthroplasty in such a situation is that the dislocation rate may be higher than what is observed when performing a hemiarthroplasty.

The rate of dislocation after hemiarthroplasty was $3.8 \%$ whatever surgical approach was used and $6.9 \%$ in the posterior approach, as reported in $2007^{(23)}$. The relative risk of dislocation was 2.9 times less, although not statistically significant, when using a dual mobility cup whatever surgical approach was used, and the relative risk of dislocation was 3.9 times less when using a dual mobility cup and a posterior approach, reaching statistical significance $(P$ $<0.05)^{(23)}$ Comparing the series of dual mobility cups in the treatment of displaced fractures of the femoral neck to recent series of bipolar hemiarthroplasties, the relative risk of dislocation appears 4-4.7 times higher for hemiarthroplasties ${ }^{(24)}$. The use of dual mobility cups in the treatment of displaced fractures of the femoral neck also appears safer in terms of the criteria of postoperative dislocation when compared to conventional cups

Dual mobility cups may be used in patients with a higher risk of dislocation such as those who are older, with increased comorbidities or a higher ASA ${ }^{(25)}$, or with neuromuscular diseases ${ }^{(26)}$. The use of a dual mobility cup increases the range of motion before impingement and dislocation. In our study, postoperative dislocation didn't occur confirming the recognized efficiency of the DM concept in preventing dislocation

In the Swedish ${ }^{(27)}$, the American ${ }^{(28)}$, the Australian ${ }^{(29)}$, the New Zealand ${ }^{(30)}$, and the Great Britain and Wales (31) registries, dislocation appears as the first or second reason for revision THA and PPF ranks in the fourth or fifth position forrevision THA. However, in the French registry ${ }^{(32)}$, PPF ranks as the second reason for revision THA and dislocation appears as the fifth reason for revision THA. In France, the use of DM in primary THA is widespread. Could this increasing use of DM explain the differences between national registries concerning the incidence of dislocation and PPF?. We encountered one case of peri-prosthetic fracture after a fall while the prosthesis remain stable and was managed with reduction and fixation and the fracture healed with good final results.

The ASA Physical Status Classification System has been in use for over 60 years. The purpose of the system is to assess and communicate a patient's pre-anesthesia medical co-morbidities. The classification system alone does not predict the perioperative risks, but used with other factors (e.g, type of surgery, frailty, level of deconditioning), it can be helpful in predicting perioperative risks. Total hip arthroplasties are of the most successful orthopaedic procedures. A retrospective study shows an ASA score of $\geq 3$ is associated with a 2.9 times $(P=0.0082)$ greater risk of re-admission for complications including instability in total joint arthroplasty patients. ${ }^{(33)}$

Hip fractures are a common and serious injury in elderly patients and they constitute the second cause of hospitalization ${ }^{(34)}$. The majority of hip fractures in elderly population mark the beginning of a downward trend in the patients' health. More than 1.6 million hip fractures occur worldwide each year. On average, hip fractures reduce life expectancy by $25 \%$ in 
comparison with the age-matched general population. In addition, hip fractures are linked to the high cost that is associated with the care of these patients and burdens on the health care systems ${ }^{(35)}$.

The main treatment goal for these injuries is early mobilization in order to prevent complications that are associated with prolonged immobilization. Another important goal is the return to pre-fracture functional activity, which can be achieved with surgery.

Elderly patients with a femoral neck fracture have improved hip scores and better functional results after the THR ${ }^{(36)}$. There are higher postoperative dislocation rates following the THR after femoral neck fracture, which is almost five times higher than that reported for THR after osteoarthritis, meta-analysis has shown dislocation rates of $10.7 \%{ }^{(37)}$. A randomized control trial comparing the internal fixation with THR in 100 patients found a dislocation rate of $22 \%$ in patients undergoing THR ${ }^{(36)}$. The use of DMC for THR in the case of a femoral neck fracture has shown a dislocation rate of $1.4 \%^{(38)}$. The current study included (5 cases) with fracture neck femur that had improved functional results with Harris hip score of mean 92.6,no one case of instability was found at the latest follow up.

The American Society of Anesthesiologists (ASA) physical status classification system was introduced in 1941 by Meyer Saklad, Emery Rovenstine, and Ivan Taylor as a grading system for the surgical patients' preoperative health ${ }^{(39,40)}$. In 1963 , the ASA suggested a revised classification regarding the physical status of preoperative patients reducing the number of classes from seven to five ${ }^{(41)}$. Specifically, it is known that the ASA classification is a good predictor of morbidity, mortality, complications, and medical problems both in the perioperative and in the postoperative period that follows hip fracture surgery in elderly patients. The current study included 14 patients with peroperative ASA classification of III and IV who were treated with cemented dual mobilty hip replacement with good functional results and no readmission for any type of reoperation except one case with periprosthetic fracture that had internal fixation.

Previous hip surgery rather than hip arthroplasty (e.g. failed fixation of hip fractures) is considered one of the risk factors of dislocation in our study due to Muscles weakness (compromised abductor function) and bone defects (which make the positioning of the implants more difficult). In our study we operate 5 cases of failed proximal femoral fixation, two of them after failed fixation by DHS, two of them after failed fixation by trochanteric plate and the last one after failed fixation by proximal femoral nail. We did not encounter any instabilty in all patients at the latest follow up and all patient had excellent functional results.

In the present study, the cemented DMC has been used for selective cases of hip replacement, which were at high risk of postoperative instability. Our early results with these implants have shown a $100 \%$ survivorship at a follow-up of 2 years without implant loosening. We have had no dislocations in our study group.

Instability remains a significant issue after both primary and revision THA. Dual mobility or tripolar unconstrained acetabular components can provide a viable alternative in preventing and treating instability. Reported outcomes of studies using DM cups with mid- to long-term follow up support their effectiveness. Concerns such accelerated wear have been emphasized, although they seem to be less significant in older, low-demand patients.

\section{Conclusion:}

In this study 1 case had complication. The complication was peri-prosthetic 
fracture after a fall while the prosthesis remain stable and was managed with reduction and fixation and the fracture healed with good final results and no intraoperative complication occurred with total complications rate 5\%. This study showed that Dual mobility cups are efficient technique in preventing hip arthroplasty instability with good clinical results.

\section{REFERENCES:}

1. Mukka SS, Mahmood SS, Sjödén GO, et al. Dual mobility cups for preventing early hip arthroplasty dislocation in patients at risk: experience in a county hospital. Orthopedic reviews. 2013; 5(2): 1-10.

2. Guyen O, Pibarot V, Vaz G, et al. Use of a dual mobility socket to manage total hip arthroplasty instability. Clinical orthopaedics and related research. 2009; 467(2): 465-72.

3. Kristiansen B, Jorgensen L, Holmich P. Dislocation following total hip arthroplasty. Arch Orthop Trauma Surg. 1985; 103:375377.

4. Dorr LD, Wolf AW, Chandler R, et al. Classification and treatment of dislocations of total hip arthroplasty. ClinOrthopRelat Res. 1983;173:151-158.

5. Soong M, Rubash HE, Macaulay W. Dislocation after total hip arthroplasty. J Am AcadOrthop Surg. 2004;12:314-321.

6. Bourne RB, Mehin R. The dislocating hip: what to do, what to do. J Arthroplasty. 2004; 19:111-114.

7. Zhao F, Ma C, Xiong C. [Treatments of dislocation after total hip replacement] ZhongguoXiu Fu Chong JianWaiKeZazhi. 2007;21:12-14.

8. Woolson ST, Rahimtoola ZO. Risk factors for dislocation during the first 3 months after primary total hip replacement. J Arthroplasty. 1999;14:662-668.

9. Williams JT, Ragland PS, Clarke S. Constrained components for the unstable hip following total hip arthroplasty: a literature review. Int Orthop 2007; 31(3): 273-7.
10. Charnley J. The long-term results of lowfriction arthroplasty of the hip performed as a primary intervention. J Bone Joint Surg Br. 1972; 54(1): 61-76.

11. Mckee GK, Watson-Farrar J. Replacement of arthritic hips by the Mckee-Farrar prosthesis. J Bone Joint Surg $\mathrm{Br}$. 1966; 48(2): 245-259.

12. Philippot R, Adam P, Rechhaus M, et al. Prevention of dislocation in total hip revision surgery using a dual mobility design. Orthop Traumatol Surg Res. 2009; 95(6): 407-413.

13. Guyen O, Pibarot V, Vaz G, et al. Unconstrained tripolar implants for primary total hip arthroplasty in patients at risk for dislocation. J Arthroplasty. 2007;22:849858.

14. Harris WH. Traumatic arthritis of the hip after dislocation and acetabular fractures. Treatment by mold arthroplasty. An endresult study using a new method of result evaluation. JBone Joint Surg Am 1969;51: 737-755.

15. Barrack RL. Preoperative planning: The adult hip. Lippincott-Raven, 1998.

16. Rady AE, Sayed MN and Abdel Aal EHM. Modified lateral approach to the hip. European hip society domestic meeting, 2004.

17. Simian E, Chatellard R, Druon J, et al. Dual mobility cup in revision total hip arthroplasty: dislocation rate and survival after 5 years. Orthopaedics \& Traumatology: Surgery \& Research. 2015; 101(5):577-81.

18. McArthur BA, Nam D, Cross MB, et al. Dual-mobility acetabular components in total hip arthroplasty. A review paper. Am J Orthop. 2013; 473-278

19. Homma Y, Baba T, Ozaki Y, et al. In total hip arthroplasty via the direct anterior approach, a dual-mobility cup prevents dislocation as effectively in hip fracture as in osteoarthritis. International orthopaedics. 2017; 41(3):491-7. 
20. Canton G, Moghnie A, Ratti C, et al. Dual mobility total hip arthroplasty in the treatment of femoral neck fracture: a systematic review of the literature. Recent Adv Arthroplast. 2018; 2(1):32-8.

21. Graversen AE, Jakobsen SS, Kristensen PK, et al. No dislocations after primary hip arthroplasty with the dual mobility cup in displaced femoral neck fracture in patients with dementia. A one-year follow-up in 20 patients. Sicot-j. 2017;3.

22. Tarasevicius $\mathrm{S}$, Jermolajevas $\mathrm{V}$, Tarasevicius R, et al. Total hip replacement for the treatment of femoral neck fractures: long-term results. Medicina (Kaunas). 2005; 41:465-469.

23. Simon P, Gouin F, Veillard D, et al. Les fractures du col du femur après 50 ans. Rev Chir Orthop 2008;94(Suppl.):S108 - 32.

24. Skinner P, Riley D, Ellery $J$, et al. Displaced subcapital fractures of the femur: a prospective randomized comparison of internal fixation, hemiarthroplasty and total hip replacement. Injury 1989;20:291-3.

25. Kim YH, Choi Y, Kim JS. Influence of patient-, design-, and surgery-related factors on rate of dislocation after primary cementless total hip arthroplasty. J Arthroplast. 2009; 24:1258-1263.

26. Fessy MH, Putman S, Viste A, et al. What are the risk factors for dislocation in primary total hip arthroplasty? A multicenter casecontrol study of 128 unstable and 438 stable hips. Orthop Traumatol Surg Res OTSR, 2017; 103:663668.

27. Swedish Hip Arthroplasty Register. Annual Report 2010. Available at: http:// www. shpr. se/ Libraries/ Documents/ AnnualReport2010- 2- eng.sflb.ashx. Accessed March 8, 2012

28. Bozic KJ, Kurtz SM, Lau E, et al. The epidemiology of revision total hip arthroplasty in the United States. J Bone Joint Surg Am. 2009; 91:128-133.

29. Australian Orthopaedic Association. National Joint Replacement Report 2011. Available at: http:// www. dmac. adelaide. edu.au/ aoanjirr/publications. Accessed October 25, 2012
30. New Zealand Orthopaedic Association. The New Zealand Joint Registry: thirteen year report. Available at: www.cdhb.govt.nz/ njr/. Accessed January 27, 2013

31. National Joint Registry for England and Wales. 9th Annual Report 2012. Available at: http://www.njrcentre.org.uk. Accessed January 27, 2013

32. Delaunay C, Hamadouche M, Girard J, et al. What are the causes for failures of primary hip arthroplasties in France? Clin Orthop. 2013; 471:3863-3869.

33. Schaeffer JF, Scott DJ, Godin JA, et al. The association of ASA class on total knee and total hip arthroplasty readmission rates in an academic hospital. The Journal of arthroplasty. 2015; 30(5):723-7.

34. Beaupre LA, Jones CA, Saunders LD, et al. Best practices for elderly hip fracture patients. Journal of general internal medicine. 2005; 20(11):1019-25.

35. Basques BA, Bohl DD, Golinvaux NS, et al. Postoperative length of stay and 30-day readmission after geriatric hip fracture: an analysis of 8434 patients. Journal of orthopaedic trauma. 2015; 29(3):e115-20.

36. Wang J, Jiang $\mathrm{B}$, Marshall RJ, et al. Arthroplasty or internal fixation for displaced femoral neck fractures: which is the optimal alternative for elderly patients? A meta-analysis. Int Orthop. 2009; 33: 1179-1187.

37. Iorio R, Healy WL, Lemos DW, et al. Displaced femoral neck fractures in the elderly. Outcomes and cost-effectiveness. Clin Orthop. 2001; 383, 229.

38. Adam P, Philippe R, Ehlinger M, et al. Dual mobility cups hip arthroplasty as a treatment for displaced fracture of the femoral neck in the elderly. A prospective, systematic, multicenter study with J.S. Luthra et al.: SICOT J 2016, 2, 435 specific focus on postoperative dislocation. Orthop Traumatol Surg Res. 2012; 98: 296-300.

39. Saklad M. Grading of patients for surgical procedures. Anesthesiology: The Journal of the American Society of Anesthesiologists. 1941; 2(3):281-4. 
40. Daabiss M. "Amaerican Society of Anaesthesiologists physical status classification," Indian Journal of Anaesthesia, 2011; 55(2): 111-115.
41. Dripps RD. "New classification of physical status," Anesthesiology, 1963; 24: 111.

\section{تركيب كؤوس أسمنتية مزدوجة الحركة أثناء جراحة استبدال مفصل الحوض بمفصل صناعي كامل

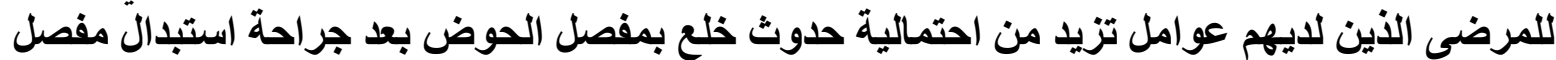

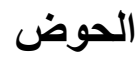

عمرو خيري محمود، أسامة محمد فرج، مجدي سعد محمود، أحمد محمد سلام، مصطفى ممدوح عشوب،

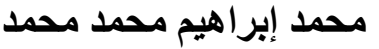

\section{نبذة مختصرة}

خلفية: مفصل الحوض هو مفصل زلالى متعدد المحاور يتمنع بدرجة عالية من الثبات ونطاق الحركة وذلك بفضل

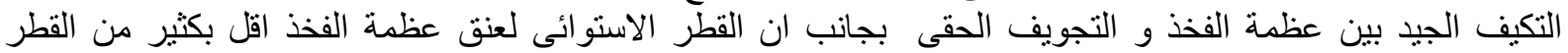

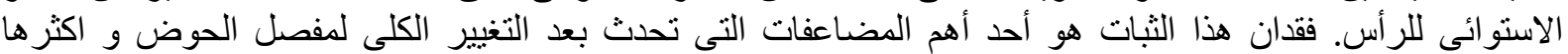

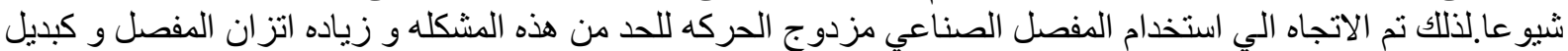

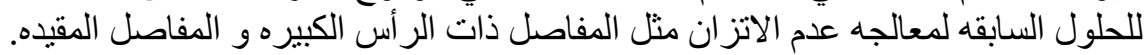

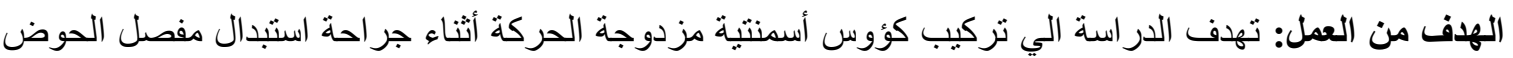

بمفصل صناعي كامل للمرضى الذين لايهم عو امل تزيد من احتمالية حدوث خلع بمفصل الحوض بعد جرئ جراحة استبدال

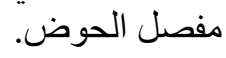

المرضى والطرق: و وقد قمنا في دراستنا بمتابعه عشرون مريضا (9 اناث و 11 ذأبور ) و التي شهدت تحسن في الحركه و الالم و بدون اية حاله خلع و حالتي التهاب سطحي تم التعامل معهم.

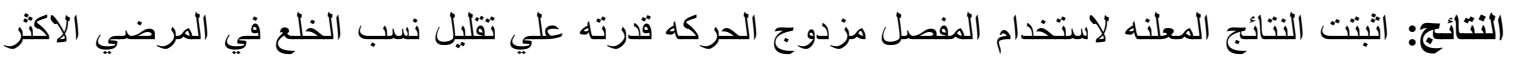

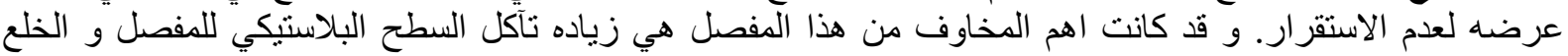

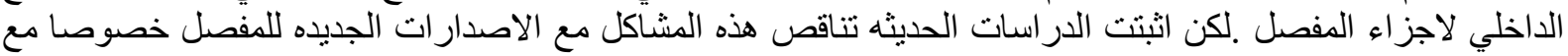

المرضي كبار السن والمرضى الذين يعانون من ضعف الجهاز العصبي و الحركي لانهم اكثر عرضده لعدم الاستقرار.

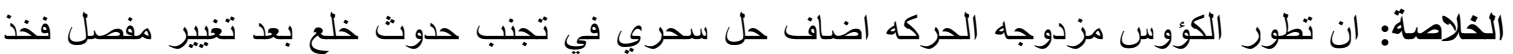

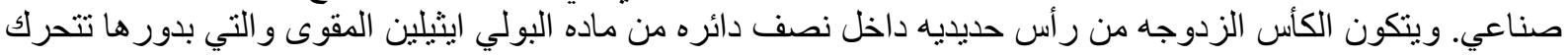

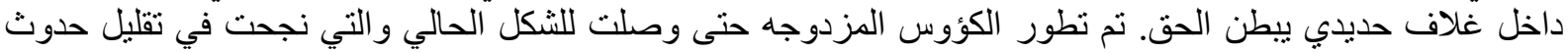

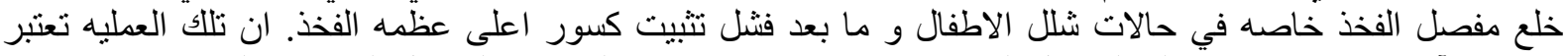

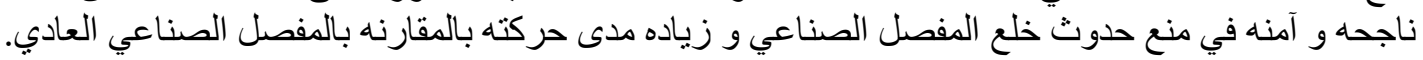
الكلمات المفتاحية: كؤوس أسمنتية مزدوجة الحركة، تحسين مستوي الحركة، خلع بين اجزاء المفصل 